\title{
BMJ
}

\section{Levothyroxine dose and risk of fractures in older adults: nested case-control study}

\author{
Marci R Turner, medical resident, ${ }^{1}$ Ximena Camacho, analyst, ${ }^{2}$ Hadas D Fischer, epidemiologist, ${ }^{2}$ Peter C \\ Austin, senior scientist, ${ }^{2}$ Geoff M Anderson, professor, ${ }^{3}$ Paula A Rochon, senior scientist, ${ }^{4}$ Lorraine L \\ Lipscombe, scientist ${ }^{4}$
}

1Department of Medicine, University of Toronto, Canada

${ }^{2}$ Institute for Clinical Evaluative Sciences, Toronto, Canada

${ }^{3}$ Department of Health Policy Management and Evaluation, University of Toronto, Canada ${ }^{4}$ Women's College Research Institute, 790 Bay Street, Toronto, ON, Canada M5G 1N8

Correspondence to: L L Lipscombe lorraine.lipscombe@wchospital.ca

Cite this as: BMJ 2011;342:d2238 doi:10.1136/bmi.d2238

\section{ABSTRACT}

Objective To quantify the effect of levothyroxine dose on risk of fractures in older adults.

Design Nested case-control study.

Setting Population based health databases, Ontario,

Canada.

Participants Adults aged 70 or more prescribed levothyroxine between 1 April 2002 and 31 March 2007 and followed for fractures until 31 March 2008. Cases were cohort members admitted to hospital for any fracture, matched with up to five controls from within the cohort who had not yet had a fracture.

Main outcome measure Primary outcome was fracture (wrist or forearm, shoulder or upper arm, thoracic spine, lumbar spine and pelvis, hip or femur, or lower leg or ankle) in relation to levothyroxine use (current, recent past, remote). Risk among current users was compared between those prescribed high, medium, and low cumulative levothyroxine doses in the year before fracture.

Results Of 213511 prevalent levothyroxine users identified, 22236 (10.4\%) experienced a fracture over a mean 3.8 years of follow-up, 18108 (88\%) of whom were women. Compared with remote levothyroxine use, current use was associated with a significantly higher risk of fracture (adjusted odds ratio 1.88, 95\% confidence interval 1.71 to 2.05), despite adjustment for numerous risk factors. Among current users, high and medium cumulative doses (>0.093 mg/day and 0.044-0.093 mg/ day) were associated with a significantly increased risk of fracture compared with low cumulative doses ( $0.044 \mathrm{mg} /$ day): 3.45 (3.27 to 3.65) and 2.62 (2.50 to 2.76), respectively.

Conclusion Among adults aged 70 or more, current levothyroxine treatment was associated with a significantly increased risk of fracture, with a strong doseresponse relation. Ongoing monitoring of levothyroxine dose is important to avoid overtreatment in this population.

\section{INTRODUCTION}

Hypothyroidism is common in older people, particularly women, ${ }^{1}$ and over $20 \%$ of older people receive levothyroxine replacement long term. ${ }^{2}$ With normal ageing, thyroid hormone production, secretion, and degradation decreases, ${ }^{3-5}$ and therefore older people with hypothyroidism have lower requirements for levothyroxine replacement than younger people. ${ }^{35}$ Most people with hypothyroidism are diagnosed in early or middle adulthood, ${ }^{6}$ thus most will have been treated for many years by the time they reach older age. Although regular monitoring of levothyroxine doses is indicated, ${ }^{78}$ evidence suggests that the dose often remains unchanged as people age ${ }^{910}$ and over $20 \%$ of older adults are overtreated, ${ }^{11-14}$ leading to iatrogenic hyperthyroidism.

Chronic hyperthyroidism may increase the risk of fractures, particularly in older people and postmenopausal women who already have a higher risk of osteoporosis and fractures. ${ }^{1315-17}$ Studies have found that higher compared with lower doses of levothyroxine replacement $^{18-20}$ and subclinical hyperthyroidism ${ }^{21}$ are associated with a lower bone density and bone quality, as measured by ultrasonography. ${ }^{22}$ An excess of thyroid hormone can also affect neuromuscular function and muscle strength ${ }^{23}$ and increase the risk of arrhythmias ${ }^{2425}$ and falls, ${ }^{15}$ which can raise the risk of fractures independent of bone density. Previous studies of the association between levothyroxine and fractures have had mixed results, ${ }^{1526-30}$ largely because of small sample sizes and the inclusion of younger, lower risk populations. This problem has not been dealt with adequately in older women, and older people in general, who are at higher risk of fractures, ${ }^{152631}$ more likely to be treated with levothyroxine, ${ }^{1132}$ and more vulnerable to adverse events related to overtreatment. ${ }^{143-36}$ Similarly, the effect of levothyroxine dose on risk for fracture has not been explored. In this population based study we quantified the risk of any fracture associated with increasing doses of replacement levothyroxine therapy in older men and women.

\section{METHODS}

We carried out a population based, retrospective cohort study with a nested case-control design using population health databases for Ontario, Canada, linked anonymously by encrypted health card 
Table 1| Baseline characteristics of cases admitted to hospital for first fracture during followup (cases) and matched with those still at risk for fracture (controls) at index date among current levothyroxine users

\begin{tabular}{|c|c|c|}
\hline Characteristics & Cases $(n=20514)$ & Controls $(n=100660)$ \\
\hline Mean (SD) age (years) & $82.27(6.81)$ & $82.17(6.80)$ \\
\hline \multicolumn{3}{|l|}{ Age group: } \\
\hline 70-79 & $7484(36)$ & $36716(36.5)$ \\
\hline $80-84$ & $9764(48)$ & $48263(47.9)$ \\
\hline$\geq 90$ & 3251 (16) & $15681(15.6)$ \\
\hline Female & $18108(88)$ & $89288(89)$ \\
\hline Resident in long term care facility & $3505(17)$ & $21306(21)$ \\
\hline \multicolumn{3}{|l|}{ Neighbourhood income (fifths): } \\
\hline 1 & $4575(22)$ & $22483(22)$ \\
\hline 5 & $3838(19)$ & $18002(18)$ \\
\hline Mean (SD) daily levothyroxine dose (mg) at index date & $0.09(0.04)$ & $0.08(0.04)$ \\
\hline \multicolumn{3}{|l|}{ Medical comorbidities* } \\
\hline Mean (SD) No of drugs prescribed in past year & $11.51(5.93)$ & $11.93(6.22)$ \\
\hline \multicolumn{3}{|l|}{ Charlson comorbidity score: } \\
\hline 0 & 3841 (19) & $16150(16)$ \\
\hline 1 & $3238(16)$ & $15276(15)$ \\
\hline$\geq 2$ & $4865(24)$ & $31624(31)$ \\
\hline Dementia & $6260(31)$ & $30409(30)$ \\
\hline Stroke & $1560(8)$ & $8901(9)$ \\
\hline Parkinson's disease & $863(4)$ & $3777(4)$ \\
\hline Cardiac arrhythmia & $6354(31)$ & $34221(34)$ \\
\hline Osteoporosis & $5544(27)$ & $22343(22)$ \\
\hline Chronic renal disease & $1946(9)$ & $12872(13)$ \\
\hline Diabetes mellitus & $4872(24)$ & $26036(26)$ \\
\hline Rheumatoid arthritis & $1780(9)$ & $8143(8)$ \\
\hline Inflammatory bowel disease & $1331(6)$ & $6749(7)$ \\
\hline Previous fracture & $2044(10)$ & $10180(10)$ \\
\hline \multicolumn{3}{|l|}{ Prescribed drugs* } \\
\hline \multicolumn{3}{|l|}{ Potentially protective drugs: } \\
\hline Bisphosphonates & $5701(28)$ & $23073(23)$ \\
\hline Statins & $6048(30)$ & $29380(29)$ \\
\hline Thiazides & $3737(18)$ & $18733(19)$ \\
\hline Other† & $4356(21)$ & $23576(23)$ \\
\hline \multicolumn{3}{|l|}{ Drugs increasing risk of fracture: } \\
\hline Inhaled or nasal corticosteroids & 2759 (13) & $14323(14)$ \\
\hline Oral corticosteroids & $1425(7)$ & $8293(8)$ \\
\hline Proton pump inhibitors & $5577(27)$ & $27944(28)$ \\
\hline SSRI/SNRIS & $5470(27)$ & $22675(23)$ \\
\hline Otherf & $1581(8)$ & $7167(7)$ \\
\hline \multicolumn{3}{|l|}{ Drugs increasing risk of fall: } \\
\hline$\beta$ blockers & $5805(28)$ & $30438(30)$ \\
\hline Sedatives & $6404(31)$ & $31082(31)$ \\
\hline Opiates & $5570(27)$ & $26715(27)$ \\
\hline Antipsychotics & $2417(12)$ & $11763(12)$ \\
\hline Other§ & $2798(14)$ & $12379(12)$ \\
\hline \multicolumn{3}{|l|}{ Health service use } \\
\hline \multicolumn{3}{|l|}{ Visits to family doctor in past year: } \\
\hline $0-5$ & $11540(56)$ & $58941(59)$ \\
\hline$\geq 6$ & $8659(42)$ & $41719(41)$ \\
\hline \multicolumn{3}{|l|}{ Visits to internist in past year: } \\
\hline $0-1$ & $16742(82)$ & $80583(80)$ \\
\hline$\geq 2$ & 3757 (18) & $20077(20)$ \\
\hline \multicolumn{3}{|l|}{ Admissions to hospital in past year: } \\
\hline 0 & $15601(76)$ & $69294(69)$ \\
\hline
\end{tabular}

numbers. The Ontario drug benefit database records all publicly funded drugs dispensed to Ontarians aged 65 or older. ${ }^{37}$ The national ambulatory care reporting system database details visits to emergency departments, and the Canadian Institute for Health Information discharge abstract database provides information on hospital admissions. Independent comparisons have validated the discharge abstract database against hospital medical records, determining accuracy of the database for procedures, diagnoses for primary admission, and major complications, ${ }^{38-41}$ and have been used extensively for data on fractures. ${ }^{42-44}$ The Ontario health insurance plan database identifies claims for physician services, and the registered persons database provides information on demographics and death. Diabetes status was obtained from the Ontario diabetes database $^{45}$ and history of thyroid cancer from the Ontario cancer registry. ${ }^{46}$

\section{Study cohort}

The cohort consisted of Ontario residents aged between 70 and 105 years with at least one prescription for levothyroxine between 1 April 2002 and 31 March 2007. People entered the cohort on the date of their first prescription. Although the Ontario drug benefit database records prescription data for patients starting at age 65 years, we excluded those under 70 to provide at least five years of drug history for all participants.

We excluded people if they had received dialysis or palliative care in the six months before entry to the cohort because of differing goals of care or bone physiology. People were also excluded if they had a history of thyroid cancer or previous hyperthyroidism before entry to the cohort, which might prompt higher dose targets for levothyroxine beyond mere replacement.

\section{Study outcomes}

The primary outcome was any fracture, defined as the first visit to an emergency department or admission to hospital for any fracture of the wrist or forearm, shoulder or upper arm, thoracic spine, lumbar spine and pelvis, hip or femur, or lower leg or ankle. We excluded fractures that occurred in the context of seizure, trauma, bone malignancy (primary or secondary), multiple myeloma, or disease. The secondary outcome was a hip or femur fracture alone, with the same contextual exclusions. (See web extra for codes according to international classification of diseases, ninth and 10th revisions.)

Participants were followed until the first occurrence of an outcome of interest, death, initiation of dialysis or palliative care, diagnosis of thyroid cancer, or the end of the study period (31 March 2008).

\section{Cases, controls, and matching}

We defined a case as any cohort member who had at least one relevant fracture during follow-up, with the date of admission to hospital for the first fracture serving as the index date. For each case we selected up to 


\begin{tabular}{lcc} 
Characteristics & Cases $(\mathrm{n}=\mathbf{2 0} 514)$ & Controls $(\mathrm{n}=1006 \mathbf{6 6 0})$ \\
$\geq 1$ & $4898(24)$ & $31366(31)$ \\
\hline At least one BMD scan in past 3 years & $6295(31)$ & $27482(27)$ \\
\hline
\end{tabular}

SSRI=selective serotonin reuptake inhibitors; SNRI=serotonin noradrenaline (norepinephrine) reuptake inhibitors.

*Unless otherwise listed, medical comorbidities and drugs were scored as yes or no; numbers of yes responses are listed.

tInclude nitrates, calcitonin, oestrogen, and selective oestrogen receptor modulators.

łnclude heparins, anticonvulsants, thiazolidinediones, aromatase inhibitors, and androgen deprivation treatments.

§Include non-SSRI or SNRI antidepressants and antiparkinsonian drugs.

five potential controls from the cohort who were still at risk for an event on the index date. Controls were assigned the same index date as their respective case. Participants could serve as a control more than once and were later eligible to become a case.

We matched controls to cases on age (within one year), sex, and duration in cohort (follow-up 30 days either way).

\section{Levothyroxine use}

Cases and controls were defined, according to use of levothyroxine, as current users, recent past users, or remote users, based on the timing of their most recent prescription for levothyroxine before the index date. The duration of a prescription was calculated as the number of days supplied for the most recent prescription in the Ontario drug benefit database plus an additional 14 days to allow for non-adherence. We classified participants as current users if the duration of their prescription encompassed the index date, recent past users if the prescription ended 15-180 days before the index date, or remote users if the prescription ended more than 180 days before the index date.

The current user subgroup was further categorised based on the cumulative dose of levothyroxine in the year before the index date. We determined this dose by calculating the total number of milligrams dispensed from all prescriptions filled in the previous 15 months intended for drug use in the year before the index date. If participants had been supplied two different concurrent prescriptions for levothyroxine, we used the more recent dose for the overlapping days. We determined the distribution of the cumulative daily dose to be a minimum of $0.018 \mathrm{mg}$ to a maximum of $158.5 \mathrm{mg}$ (median $24.94 \mathrm{mg}$ ). Low dose users were those with a cumulative daily dose in the lowest 25th centile of this distribution, medium dose users between the 25 th and 75 th centiles, and high dose users above the 75 th centile.

For current users, we examined all the doses of levothyroxine prescribed in the year before the index date. If the dose changed, we specified the direction of the most recent dose change before the index date. An increase in dose was considered to have occurred if the most recent dose before the index date was higher than the second most recent dose before the index date. A dose reduction was noted if the most recent dose before the index date was lower than the second most recent dose before the index date.

\section{Statistical analysis}

We used conditional logistic regression to estimate associations between levothyroxine use and fracture outcomes in the matched cases and controls, controlling for potential confounders such as fifth of neighbourhood income (from 1 to 5 for the lowest to highest income fifth), Charlson comorbidity index, and history of health service use at the index date. This logistic regression also controlled for other confounders, including previous fractures, risk factors for fracture, and comorbid conditions in the five years before the index date, and the use of other prescription drugs in the year before the index date. The analysis was done using SAS version 9.2.

For our primary analysis we compared the association between any fracture and current use of levothyroxine compared with remote use. We also examined the association between recent past use compared with remote use and fractures to determine whether a residual effect remained after recent discontinuation of levothyroxine. We then examined the association between levothyroxine dose and any fracture in the subgroup of current users. We compared the risk of fracture in the high and medium dose groups with that in the low dose group.

For our first secondary analysis, we examined the outcome of hip or femur fracture specifically as most of these fractures are non-traumatic and carry the greatest morbidity and mortality for older people. We created a new set of cases and controls, whereby cases were all cohort members who had experienced a hip or femur fracture during the observation period and controls were those who did not experience a hip or femur fracture. We repeated the primary analyses for this outcome. Secondly, we compared the risk of fracture between people who had changed dose in the past year with those who had not, considering any dose change as well as a dose increase or decrease. Thirdly, we stratified the cases and controls by sex and repeated all the primary and secondary analyses for men and women separately. We also tested for an interaction between sex and levothyroxine use for each analysis, to assess whether sex modified the effect of levothyroxine on the risk of fractures. ${ }^{47}$

\section{RESULTS}

The study cohort consisted of 213511 adults using levothyroxine, with a mean age of 82 and followed for a mean of 3.83 years. In total, $22236(10.4 \%)$ people (18 $108(88 \%)$ women) sustained at least one fracture and $58063(27.2 \%)$ died during follow-up. Cases were more likely than controls to have a diagnosis of osteoporosis and to use bisphosphonates (table 1). Among the cases, 20514 (92.3\%) were current users of levothyroxine at the index date. Among these, $3071(15.0 \%)$ were low dose users, with a mean daily dose of $0.046 \mathrm{mg}$ (SD $0.029 \mathrm{mg}$ ), as defined by a cumulative daily dose of less than $15.95 \mathrm{mg}$ over the previous year (<0.044 mg daily); 10907 (53.2\%) were medium dose users, with a mean daily dose of 0.076 (SD 0.026$) \mathrm{mg}$, as defined by a cumulative daily dose of 
Table 2|Baseline characteristics of current levothyroxine users only, categorised by cumulative dose of levothyroxine at index date for cases and their matched controls. Values are numbers (percentages) unless stated otherwise

\begin{tabular}{|c|c|c|c|c|c|c|}
\hline \multirow[b]{3}{*}{ Characteristics } & \multicolumn{6}{|c|}{ Cumulative dose in current users } \\
\hline & \multicolumn{2}{|c|}{ Low (<0.044 mg/day) } & \multicolumn{2}{|c|}{ Medium $(0.044-0.093 \mathrm{mg} /$ day $)$} & \multicolumn{2}{|c|}{ High (>0.093 mg/day) } \\
\hline & Cases $(n=3071)$ & Controls $(n=27$ 106) & Cases (n=10 907) & Controls $(n=49798)$ & Cases $(n=6521)$ & Controls $(n=23756)$ \\
\hline Mean (SD) age (years) & $83.14(6.82)$ & $82.56(6.53)$ & $82.65(6.86)$ & $82.53(6.81)$ & $81.22(6.59)$ & $80.95(6.94)$ \\
\hline \multicolumn{7}{|l|}{ Age group: } \\
\hline $70-74$ & $971(32)$ & $9185(34)$ & $3775(35)$ & $17094(34)$ & $2738(42)$ & $10437(44)$ \\
\hline $80-84$ & $1515(49)$ & $13589(50)$ & $5257(48.1)$ & $24340(49)$ & $2992(46)$ & $10334(44)$ \\
\hline$\geq 90$ & 585 (19) & $4332(16)$ & 1875 (17) & $8364(17)$ & $791(12)$ & 2985 (13) \\
\hline Women & $2592(84)$ & $23157(85)$ & $9816(90)$ & $44992(90)$ & $5700(87)$ & $21139(89)$ \\
\hline Resident in long term care facility & $645(21)$ & $6501(24)$ & 1819 (17) & $10005(20)$ & $1041(16)$ & $4800(20)$ \\
\hline \multicolumn{7}{|l|}{ Neighbourhood income (fifths): } \\
\hline 1 & $671(22)$ & $6116(23)$ & $2428(22)$ & $11062(22)$ & $1476(23)$ & $5305(22)$ \\
\hline 5 & $525(17)$ & $4669(17)$ & $2137(20)$ & $9073(18)$ & 1176 (18) & $4260(18)$ \\
\hline $\begin{array}{l}\text { Mean (SD) daily levothyroxine dose } \\
(\mathrm{mg}) \text { at index date }\end{array}$ & $0.05(0.03)$ & $0.05(0.03)$ & $0.08(0.03)$ & $0.08(0.03)$ & $0.12(0.04)$ & $0.12(0.04)$ \\
\hline \multicolumn{7}{|l|}{ Medical comorbidities } \\
\hline $\begin{array}{l}\text { Mean (SD) No of drugs prescribed in } \\
\text { past year }\end{array}$ & $11.87(6.17)$ & $12.02(6.40)$ & $11.31(5.84)$ & $11.66(6.05)$ & $11.66(5.97)$ & $12.41(6.33)$ \\
\hline \multicolumn{7}{|l|}{ Charlson comorbidity score: } \\
\hline 0 & 597 (19) & $4329(16)$ & 2031 (19) & $8074(16)$ & 1213 (19) & $3747(16)$ \\
\hline 1 & $532(17)$ & $4417(16)$ & $1697(16)$ & $7408(15)$ & 1009 (15) & $3451(15)$ \\
\hline$\geq 2$ & $813(26)$ & $8608(32)$ & $2484(23)$ & $15050(30)$ & $1568(24)$ & $7966(34)$ \\
\hline Dementia & $1131(37)$ & $8918(33)$ & $3299(30)$ & $14866(30)$ & $1830(28)$ & $6625(28)$ \\
\hline Stroke & $286(9)$ & $2552(9)$ & $779(7)$ & $4155(8)$ & $495(8)$ & $2194(9)$ \\
\hline Parkinson's disease & $136(4)$ & $1101(4)$ & $469(4)$ & $1874(4)$ & $258(4)$ & $802(3)$ \\
\hline Cardiac arrhythmia & $1084(35)$ & $9690(36)$ & $3347(31)$ & $16715(34)$ & $1923(29)$ & $7816(33)$ \\
\hline Osteoporosis & $857(28)$ & $6053(22)$ & $3090(28)$ & $11481(23)$ & $1597(24)$ & $4809(20)$ \\
\hline Chronic renal disease & $352(11)$ & $3694(14)$ & $990(9)$ & $6224(12)$ & $604(9)$ & 2954 (12) \\
\hline Diabetes mellitus & $693(23)$ & $6857(25)$ & $2403(22)$ & $12059(24)$ & $1776(27)$ & $7120(30)$ \\
\hline Rheumatoid arthritis & $257(8)$ & $2134(8)$ & $901(8)$ & $3822(8)$ & $622(10)$ & $2187(9)$ \\
\hline Inflammatory bowel disease & $213(7)$ & $1818(7)$ & $702(6)$ & $3310(7)$ & $416(6)$ & $1621(7)$ \\
\hline Previous fracture & $447(15)$ & 3579 (13) & $1015(9)$ & $4511(9)$ & $582(9)$ & $2090(9)$ \\
\hline \multicolumn{7}{|l|}{ Prescribed drugs } \\
\hline \multicolumn{7}{|l|}{ Potentially protective drugs: } \\
\hline Bisphosphonates & $842(27)$ & $6081(22)$ & 3149 (29) & $11989(24)$ & $1710(26)$ & $5003(21)$ \\
\hline Statins & $860(28)$ & $7821(29)$ & $3222(30)$ & $14679(29)$ & $1966(30)$ & $6880(29)$ \\
\hline Thiazides & $495(16)$ & 5017 (19) & 2048 (19) & 9199 (18) & 1194 (18) & 4517 (19) \\
\hline Other† & $651(21)$ & $6421(24)$ & $2281(21)$ & $11391(23)$ & $1424(22)$ & $5764(24)$ \\
\hline \multicolumn{7}{|l|}{ Drugs increasing risk of fracture: } \\
\hline Inhaled or nasal corticosteroids & $429(14)$ & $3743(14)$ & 1416 (13) & $6980(14)$ & $914(14)$ & $3600(15)$ \\
\hline Oral corticosteroids & $201(7)$ & $1986(7)$ & $773(7)$ & $4161(8)$ & $451(7)$ & $2146(9)$ \\
\hline Proton pump inhibitors & $844(27)$ & $7455(28)$ & $2981(27)$ & $13862(28)$ & $1752(27)$ & $6627(28)$ \\
\hline SSRI or SNRIS & $893(29)$ & $6204(23)$ & $2866(26)$ & $11069(22)$ & $1711(26)$ & $5402(23)$ \\
\hline Other & $249(8)$ & $1977(7)$ & $720(7)$ & $3150(6)$ & $612(9)$ & $2041(9)$ \\
\hline \multicolumn{7}{|l|}{ Drugs increasing risk of fall: } \\
\hline$\beta$ blockers & $878(29)$ & $8230(30)$ & $3055(28)$ & $14735(30)$ & $1872(29)$ & $7473(31)$ \\
\hline Sedatives & $979(32)$ & $8118(30)$ & $3357(31)$ & $15393(31)$ & $2068(32)$ & $7571(32)$ \\
\hline Opiates & $851(28)$ & $6673(25)$ & $2821(26)$ & $12817(26)$ & $1898(29)$ & $7225(30)$ \\
\hline Antipsychotics & $432(14)$ & 3415 (13) & $1271(12)$ & $5617(11)$ & $714(11)$ & $2731(11)$ \\
\hline Other§ & $399(13)$ & $3296(12)$ & 1464 (13) & $5802(12)$ & $935(14)$ & $3281(14)$ \\
\hline \multicolumn{7}{|l|}{ Health service use } \\
\hline \multicolumn{7}{|l|}{ Visits to family doctor in past year: } \\
\hline $0-5$ & $1658(54)$ & $15455(57)$ & $6221(57)$ & $29850(60)$ & $3661(56)$ & $13636(57)$ \\
\hline$\geq 6$ & $1413(46)$ & $11651(43)$ & $4686(43)$ & $19948(40)$ & $2860(44)$ & $10120(43)$ \\
\hline \multicolumn{7}{|l|}{ Visits to internist in past year: } \\
\hline $0-1$ & $2429(79)$ & $21526(79)$ & $9006(83)$ & $40292(81)$ & $5307(81)$ & $18765(79)$ \\
\hline$\geq 2$ & $642(21)$ & $5580(21)$ & 1901 (17) & 9506 (19) & 1214 (19) & $4991(21)$ \\
\hline
\end{tabular}




\begin{tabular}{|c|c|c|c|c|c|c|}
\hline \multirow[b]{3}{*}{ Characteristics } & \multicolumn{6}{|c|}{ Cumulative dose in current users } \\
\hline & \multicolumn{2}{|c|}{ Low (く0.044 mg/day) } & \multicolumn{2}{|c|}{ Medium (0.044-0.093 mg/day) } & \multicolumn{2}{|c|}{ High (>0.093 mg/day) } \\
\hline & Cases $(n=3071)$ & Controls $(n=27$ 106) & Cases $(n=10907)$ & Controls $(n=49798)$ & Cases $(n=6521)$ & Controls $(n=23756)$ \\
\hline \multicolumn{7}{|l|}{ Admissions to hospital in past year: } \\
\hline 0 & $2093(68)$ & $17225(64)$ & $8374(77)$ & $35240(71)$ & $5134(79)$ & $16829(71)$ \\
\hline$\geq 1$ & $978(32)$ & $9881(36)$ & $2533(23)$ & $14558(29)$ & $1387(21)$ & $6927(29)$ \\
\hline At least one BMD scan in past 3 years & $839(27)$ & $6996(26)$ & $3504(32)$ & $14178(28)$ & $1952(30)$ & $6308(27)$ \\
\hline \multicolumn{7}{|c|}{$\begin{array}{l}\text { SSRI=selective serotonin reuptake inhibitors; SNRI=serotonin noradrenaline (norepinephrine) reuptake inhibitors. } \\
\text { *Unless otherwise listed, medical comorbidities and drugs were scored as yes or no and numbers of yes responses are listed. } \\
\text { †Include nitrates, calcitonin, oestrogen, and selective oestrogen receptor modulators. } \\
\text { łlnclude heparins, anticonvulsants, thiazolidinediones, aromatase inhibitors, and androgen deprivation treatments. } \\
\text { §Include non-SSRI or SNRI antidepressants and antiparkinsonian drugs. }\end{array}$} \\
\hline
\end{tabular}

15.95-34 mg (0.044-0.093 mg daily); and 6521 (31.8\%) were high dose users, with a mean daily dose of 0.122 (SD 0.041) $\mathrm{mg}$, defined by a cumulative daily dose greater than $34 \mathrm{mg}(>0.093 \mathrm{mg}$ daily). Among the current users, those receiving lower doses of levothyroxine were more likely to live in a long term care facility; to have medical comorbidities affecting fracture risk, such as dementia ${ }^{4849}$ or cardiac arrhythmia ${ }^{50}$; and to have other risk factors for fracture, such as a previous fracture $^{335152}$ or use of selective serotonin reuptake inhibitors or serotonin noradrenaline (norepinephrine) reuptake inhibitors. ${ }^{5354}$ Participants receiving higher doses of levothyroxine were more likely to have diabetes and were less likely to have osteoporosis (table 2).

\section{Association between levothyroxine treatment and fractures}

Compared with remote use of levothyroxine (discontinued $>180$ days before index date), current and recent past use (discontinued within 15 to 180 days of index date) were both associated with a significantly increased risk of any fracture (adjusted odds ratio $1.88,95 \%$ confidence interval 1.71 to 2.05 and 1.33 , 1.19 to 1.48$)$. Current use compared with remote use was also significantly associated with an increased risk of hip fractures (table 3).

Among current users, high cumulative doses of levothyroxine $(>0.093 \mathrm{mg} /$ day) and medium cumulative doses (0.044-0.093 mg/day) were associated with an increased risk of fractures compared with low $(<0.044 \mathrm{mg} /$ day $)$ doses $(3.45,3.27$ to 3.65 and 2.62, 2.50 to 2.76 ). A dose related increase in the risk of fractures was also found for hip fractures (table 4).

Compared with remote use of levothyroxine, current use was associated with a higher risk of any fracture in both sexes and with a higher risk of hip fracture in women. A dose related association was observed for hip fractures as well as for any fracture in both men and women (table 5). In addition, interactions between sex and levothyroxine use and dose were significant (table 5). The risk of fracture for current versus remote use was higher in women than in men, and within the current user group high dose compared with low dose was associated with a greater risk in men than in women (table 5).
A change in levothyroxine dose in the previous year was also associated with fewer fractures, although this was not a significant finding in the adjusted analysis $(0.98,0.95$ to 1.02$)$. However, significant associations were found when direction of dose change was taken into account: an increase in dose in the previous year was associated with a significant decrease in risk of fracture $(0.90,0.86$ to 0.94$)$ and a decrease in dose was associated with a significantly increased risk of fracture $(1.09,1.04$ to 1.15$)$. Further adjustment of dose change by dose categories was not done as only $11-13 \%$ of cases changed dose, and the relative effect of these changes on risk of fracture was small compared with the risk estimates from our primary analysis.

\section{DISCUSSION}

Our population based study found a significant association between current levothyroxine use and increased risk of fracture among older people $(>70$ years). Furthermore, an increased risk remained even among those who discontinued levothyroxine within six months, and a strong dose-response relation was observed between current use and risk of fracture. This increased risk of fractures with treatment was found in both sexes and persisted despite adjustment for multiple fracture risk factors. Levothyroxine was also associated with an increase in hip fractures specifically, which carry the greatest morbidity and mortality for older adults. ${ }^{55}$ Our findings provide evidence that levothyroxine treatment may increase the risk of fragility fractures in older people even at conventional dosages, suggesting that closer monitoring and modification of treatment targets may be warranted in this vulnerable population.

\section{Comparison with other studies}

Previous studies examining the association between levothyroxine replacement and fracture risk have yielded inconsistent conclusions and have not tackled the role of levothyroxine dose in this relation. Studies largely in younger people $\mathrm{e}^{30}$ and postmenopausal women ${ }^{1526}$ have not found a relation between any fracture or hip fractures and levothyroxine use. Secondary analyses of other studies have only found associations between levothyroxine replacement and hip fractures in men $^{27}$ and forearm fractures in older adults within the first two years of treatment. ${ }^{29}$ Recently a population 
Table 3|Risk for any fracture or hip fracture among all levothyroxine users, stratified by levothyroxine use

\begin{tabular}{|c|c|c|c|c|c|}
\hline \multirow{2}{*}{$\begin{array}{l}\text { Fracture type, } \\
\text { levothyroxine use }\end{array}$} & \multicolumn{2}{|c|}{ No (\%) of participants } & \multicolumn{2}{|c|}{ Odds ratio $(95 \% \mathrm{Cl})$} & \multirow[b]{2}{*}{$P$ value } \\
\hline & Cases & Controls & Unadjusted & Adjusted* & \\
\hline \multicolumn{6}{|l|}{ Any fracture: } \\
\hline Current use $†$ & $20514(92.3)$ & $96528(88.3)$ & 1.88 (1.72 to 2.06$)$ & 1.88 (1.71 to 2.05$)$ & $<0.001$ \\
\hline Recent past use $\neq$ & $1142(5.1)$ & $7734(7.1)$ & 1.31 (1.18 to 1.46$)$ & 1.33 (1.19 to 1.48$)$ & $<0.001$ \\
\hline Remote use§ & $580(2.6)$ & $5111(4.7)$ & 1.00 & - & - \\
\hline \multicolumn{6}{|l|}{ Hip fracture: } \\
\hline Current use $†$ & $7763(92.1)$ & $36582(88.5)$ & 1.58 (1.38 to 1.82$)$ & 1.55 (1.35 to 1.78$)$ & $<0.001$ \\
\hline Recent past use $\neq$ & $418(5.0)$ & $2888(7.0)$ & 1.09 (0.92 to 1.29$)$ & 1.12 (0.94 to 1.33$)$ & 0.203 \\
\hline Remote use§ & $252(3.0)$ & $1884(4.6)$ & 1.00 & - & - \\
\hline
\end{tabular}

*Adjusted for personal and clinical confounders listed in table 1.

†Number of days supplied for most recent prescription plus 14 days overlapping index date.

$\ddagger$ Prescription ended $15-180$ days before index date.

§Prescription ended $>180$ days before index date (reference group).

based cohort study of people aged over 18 years found an increased risk of fractures only in those taking excess levothyroxine replacement based on suppression of serum thyroid stimulating hormone levels. ${ }^{28}$ Our study specifically focused on older adults, who have a higher baseline risk of fracture ${ }^{152656}$ and are more vulnerable to excessive levothyroxine replacement. ${ }^{11-14}$

\section{Clinical explanation of results}

In our study, current use of higher doses of levothyroxine was associated with a higher risk of fractures compared with lower doses, despite the presence of fewer risk factors for fracture in high dose users, such as previous fractures, ${ }^{335152}$ stroke, ${ }^{5758}$ arrhythmia, ${ }^{50}$ dementia, ${ }^{4849}$ and the use of certain drugs. Higher doses of levothyroxine are more likely to be associated with iatrogenic hyperthyroidism, ${ }^{3659}$ which can decrease bone quality ${ }^{22}$ and bone mineral density, ${ }^{60}$ leading to a higher risk of fracture. Excess thyroid hormone can also increase the risk of arrhythmias ${ }^{2425}$ and muscle weakness ${ }^{23}$ in older people, which can contribute to a greater risk of falls.

This association is particularly of concern for women, given that they were almost $90 \%$ of levothyroxine users in our study. In addition, current use of levothyroxine was associated with a larger risk of fracture in women than in men. This may be related to differences in body size and pharmacokinetics between the sexes. ${ }^{142861}$ The notion that the same sized dose of levothyroxine may have different effects in women and men is consistent with the finding that the doseresponse curve in current users is steeper in men than in women. Further studies are needed to explore better how the effect of levothyroxine on bone and fracture risk differs between women and men.

Although we were not able to measure thyroid function in our study, we attempted to assess whether recent dose changes, as a measure of recent thyroid monitoring, had an effect on fracture risk. We found a slight increase in fracture risk associated with a decrease in dose and a small protective effect associated with an increase. The mechanism behind these effects is not clear. A recent decrease in dose may reflect previous hyperthyroidism, which may predispose to fractures, and an increase in dose may reflect previous hypothyroidism, which may have been protective for bone and reduce the risk of fractures. The small magnitude of this effect limits its clinical significance.

\begin{tabular}{|c|c|c|c|c|c|}
\hline \multirow{2}{*}{$\begin{array}{l}\text { Fracture type, cumulative } \\
\text { levothyroxine dose } \dagger(\mathrm{mg})\end{array}$} & \multicolumn{2}{|c|}{ No (\%) of participants } & \multicolumn{2}{|c|}{ Odds ratio $(95 \% \mathrm{Cl})$} & \multirow[b]{2}{*}{$P$ value } \\
\hline & Cases & Controls & Unadjusted & Adjusted $\ddagger$ & \\
\hline \multicolumn{6}{|l|}{ Any fracture: } \\
\hline Low§ ( $(0.044$ mg/day) & $3071(15.0)$ & $27106(26.9)$ & 1.00 & - & - \\
\hline Medium I (0.044-0.093 mg/day) & $10907(53.2)$ & $49798(49.5)$ & $2.61(2.49$ to 2.75$)$ & $2.62(2.50$ to 2.76$)$ & $<0.001$ \\
\hline $\mathrm{High}^{\star \star}(>0.093 \mathrm{mg} /$ day $)$ & $6521(31.8)$ & $23756(23.6)$ & $3.38(3.20$ to 3.56$)$ & 3.45 (3.27 to 3.65$)$ & $<0.001$ \\
\hline \multicolumn{6}{|l|}{ Hip fracture: } \\
\hline Low§ («0.044 mg/day) & $1261(16.3)$ & $10635(28.0)$ & 1.00 & - & - \\
\hline MediumT (0.044-0.093 mg/day) & $4110(53.0)$ & $18861(49.7)$ & 2.55 (2.36 to 2.77$)$ & 2.54 (2.34 to 2.75$)$ & $<0.001$ \\
\hline $\mathrm{High}^{\star \star}(>0.093 \mathrm{mg} /$ day $)$ & $2385(30.8)$ & $8438(22.2)$ & $3.43(3.14$ to 3.75$)$ & 3.39 (3.10 to 3.70$)$ & $<0.001$ \\
\hline
\end{tabular}

*Number of days supplied for most recent prescription plus 14 days overlapping index date.

†Total milligrams of levothyroxine dispensed from all prescriptions in previous 15 months for use in 365 days before index date.

$\ddagger$ Adjusted for personal and clinical confounders listed in table 1.

§Participants whose cumulative levothyroxine dose was in lowest 25 th centile of cumulative doses among all cases (mean daily dose 0.046 mg/day). IParticipants whose cumulative levothyroxine doses was between 25th and 75th centiles of cumulative doses among all cases (mean daily dose $0.076 \mathrm{mg} /$ day).

**Participants whose cumulative levothyroxine doses exceeded 75 th centile of cumulative doses among all cases (mean daily dose $0.122 \mathrm{mg} / \mathrm{day}$ ). 
Table 5|Odd ratios for fractures stratified by sex, time of levothyroxine use, and dose

\begin{tabular}{|c|c|c|c|c|c|c|c|c|}
\hline \multirow[b]{2}{*}{$\begin{array}{l}\text { Fracture type, time and dose of } \\
\text { levothyroxine use }\end{array}$} & \multicolumn{3}{|c|}{ Men } & \multicolumn{3}{|c|}{ Women } & \multicolumn{2}{|c|}{$\begin{array}{l}\text { Interaction between } \\
\text { sex and drug use }\end{array}$} \\
\hline & No (\%) of cases & $\begin{array}{l}\text { Adjusted odds } \\
\text { ratio* }(95 \% \mathrm{Cl})\end{array}$ & $P$ value & No (\%) of cases & $\begin{array}{l}\text { Adjusted odds } \\
\text { ratio* }(95 \% \mathrm{Cl})\end{array}$ & $P$ value & z statistic & $P$ value \\
\hline \multicolumn{9}{|l|}{ Any fracture: } \\
\hline Current† $v$ remote & $2395(89.4)$ & $1.42(1.15$ to 1.76$)$ & 0.001 & $18119(92.6)$ & 1.98 (1.80 to 2.19$)$ & $<0.001$ & -2.80 & 0.0051 \\
\hline Low $\ddagger$ (८0.044 mg/day) & $479(20.0)$ & & & $2592(14.3)$ & & & & \\
\hline Medium§ (0.044-0.093 mg/day) & $1091(45.6)$ & $3.18(2.74$ to 3.67$)$ & $<0.001$ & $9816(54.2)$ & $2.56(2.42$ to 2.70$)$ & $<0.001$ & 2.73 & 0.0063 \\
\hline $\operatorname{High}^{\star \star}(>0.093 \mathrm{mg} /$ day $)$ & $821(34.3)$ & 4.67 (3.99 to 5.47$)$ & $<0.001$ & $5700(31.5)$ & 3.31 (3.13 to 3.51$)$ & $<0.001$ & 4.00 & 0.0001 \\
\hline \multicolumn{9}{|l|}{ Hip fracture: } \\
\hline Current† $v$ remote & $1019(89.2)$ & $1.14(0.83$ to 1.57$)$ & 0.4101 & $6744(92.5)$ & 1.65 (1.41 to 1.92$)$ & $<0.001$ & -2.04 & 0.041 \\
\hline Low $\ddagger$ («0.044 mg/day) & $217(21.3)$ & & & $1044(15.5)$ & & & & \\
\hline Medium§ (0.044-0.093 mg/day) & $440(43.2)$ & 3.12 (2.49 to 3.89$)$ & $<0.001$ & $3670(54.5)$ & $2.46(2.26$ to 2.68$)$ & $<0.001$ & 1.94 & 0.052 \\
\hline $\mathrm{High}^{\star *}(>0.093 \mathrm{mg} /$ day $)$ & $361(35.5)$ & 5.05 (3.96 to 6.43$)$ & $<0.001$ & $2024(30.0)$ & $3.19(2.90$ to 3.51$)$ & $<0.001$ & 3.46 & 0.0005 \\
\hline
\end{tabular}

Unadjusted data not shown. Cumulative dose is total milligrams of levothyroxine dispensed from all prescriptions in previous 15 months for use in 365 days before index date.

${ }^{*}$ Adjusted for personal and clinical confounders listed in table 1.

†Number of days supplied for most recent prescription plus 14 days overlapping index date.

†Reference group: participants whose cumulative levothyroxine dose was in lowest 25 th centile of cumulative doses among all cases (mean daily dose $0.046 \mathrm{mg} /$ day).

§Participants whose cumulative levothyroxine doses was between 25th and 75 th centiles of cumulative doses among all cases (mean daily dose 0.076 mg/day).

**Participants whose cumulative levothyroxine doses exceeded 75 th centile of cumulative doses among all cases (mean daily dose $0.122 \mathrm{mg} / \mathrm{day}$ ).

\section{Clinical application of results}

As levothyroxine requirements decrease with age, iatrogenic hyperthyroidism is more common in older people. ${ }^{35}$ Despite this, studies show that for many people levothyroxine dosage is not adjusted as they age because either monitoring for thyroid dysfunction may be not be carried out or indicated dose adjustments identified by monitoring may not be implemented..$^{9-14}$ While the optimal levothyroxine dose for adults is $1.6-1.8 \mu \mathrm{g} / \mathrm{kg} /$ day, ${ }^{19}$ older people often require much lower doses to achieve euthyroidism, and most recommend a reduced dose of $0.5 \mu \mathrm{g} /$ $\mathrm{kg} /$ day in seniors (age $>65$ years). ${ }^{162}$ While the dosages observed in our study were largely appropriate for younger adults, the average daily doses in the medium and high dose categories (0.076 and $0.122 \mathrm{mg} /$ day) may have exceeded the recommendation for most people aged over 70. It is also possible that levothyroxine treatment may have deleterious effects on bone even in people who are biochemically euthyroid. Recently it has been shown that the risk of vertebral fractures in older adults is increased with serum thyroid stimulating hormone use in the lower range of normal limits. ${ }^{63}$ To minimise the risk of fracture further work is necessary to determine whether bone can be affected by "euthyroid" doses of levothyroxine and whether treatment targets need to be adjusted in older people whose true "normal" thyroid stimulating hormone levels may be higher than thought. ${ }^{64}$

\section{Strengths and limitations of the study}

Some limitations of our study merit mention. Laboratory and radiological data, such as serum thyroid stimulating hormone levels and radiology reports, were not available from our databases. Also, without access to clinical information we were unable to verify the indication for levothyroxine treatment in cohort members that affects dosing. This might potentially explain the larger than expected proportion of people (nearly
$8 \%$ ) who had discontinued levothyroxine, given that it is generally continued lifelong when prescribed for hypothyroidism. However, we minimised variation of indication as much as possible by excluding people with previous hyperthyroidism or thyroid cancer, and less than $1 \%$ of the study participants had undergone thyroidectomy. We were unable to measure other factors that may affect the association between levothyroxine and fracture risk, such as body mass index, ${ }^{65}$ family history, smoking, caffeine or alcohol use, ${ }^{15}$ or non-prescription drug use such as calcium and vitamin D. Misclassification and selection bias are also potential threats to validity in observational studies such as ours. We minimised the potential for misclassification by using hospital based fractures as our outcome and by considering cumulative levothyroxine dosage over the previous year rather than a single prescription to estimate drug use. ${ }^{66}$ Cases and controls were matched on age, sex, and duration in the study cohort, and we used regression techniques to adjust for potential confounders. The nested case-control design is commonly used in pharmacosurveillance research and provides estimates of effects that are consistent with those obtained from time to event analysis. ${ }^{67-70}$ In addition, risk factors for fractures and comorbidities were more common among low dose levothyroxine users, which would argue against a selection bias explaining the association between high dose levothyroxine and fractures. The dose-response relation for levothyroxine doses commonly prescribed in practice also supports a clinically relevant association between levothyroxine treatment and fractures in older people. In using fractures resulting in visits to the emergency department or hospital admission as our outcome, it is possible that we failed to capture more minor, asymptomatic fractures that did not seek or warrant hospital based intervention, such as vertebral fractures. The effect of this on our results is possibly minimal, however, given that our analysis using the outcome of hip fractures alone, a 


\section{WHAT IS ALREADY KNOWN ON THIS TOPIC}

Excess levothyroxine and subclinical hyperthyroidism are associated with lower bone density as well as other risk factors for falls and fractures

\section{WHAT THIS STUDY ADDS}

Before this study the effect of levothyroxine dose on fracture outcomes was not known, particularly in the at risk population of older people ( 270 years)

In this population, higher doses of levothyroxine treatment were associated with a twofold to threefold increased risk of fracture compared with lower doses

highly specific fracture requiring regular admission to hospital, yielded the same associations.

\section{Conclusion}

Our study shows that levothyroxine treatment is associated with a higher risk of fractures in a dose-response manner in older adults, and that dosages commonly used in clinical practice, especially over $0.093 \mathrm{mg}$ a day, may be excessive for this population. While further work is needed to determine whether these doses are associated with iatrogenic hyperthyroidism in this population, our study raises concerns that levothyroxine treatment targets may need to be modified in elderly people and that dose monitoring remains essential even into older age.

This work was supported by a team grant (OTG-88591) from the Canadian Institutes of Health Research (CIHR) and by a CIHR interdisciplinary capacity enhancement grant (HOA-80075). LLL is supported by a Canadian Diabetes Association/CIHR clinician scientist award. PCA is supported by a career investigator award from the Heart and Stroke Foundation of Ontario. GMA is supported by the University of Toronto chair in health management strategies.

Contributors: MRT and LLL designed the study, interpreted the data, and drafted the original manuscript. They are the guarantors. XC assisted with the study design and data acquisition and edited the manuscript. HDF assisted with the study design and edited the manuscript. PCA, GMA, and PAR assisted with the study design and interpretation of the data and edited the manuscript. All authors had full access to all of the data in the study and take responsibility for the integrity of the data and the accuracy of the data analysis. The opinions, results, and conclusions are those of the authors and no endorsement by the Ministry of Health and Long-Term Care or by the Institute for Clinical Evaluative Sciences is intended or should be inferred.

Competing interests: All authors have completed the Unified Competing Interest form at www.icmje.org/coi_disclosure.pdf (available on request from the corresponding author) and declare: no support from any organisation for the submitted work; no financial relationships with any organisations that might have an interest in the submitted work in the previous three years; and no other relationships or activities that could appear to have influenced the submitted work.

Ethical approval: This project was approved by the institutional review board at Sunnybrook Health Sciences Centre, Toronto, Ontario, Canada. Data sharing: The technical appendix, statistical code, and dataset are available from the corresponding author at lorraine.lipscombe@wchospital.ca

1 Roberts CG, Ladenson PW. Hypothyroidism. Lancet 2004;363:793-803.

2 Canadian Institute for Health Information. Drug use among seniors on public drug programs in Canada, 2002 to 2008. CIHI, 2010.

3 Mooradian AD. Normal age-related changes in thyroid hormone economy. Clin Geriatr Med 1995;11:159-69.

4 Robbins J. Factors altering thyroid hormone metabolism. Environ Health Perspect 1981;38:65-70.

5 Sawin CT, Geller A, Hershman JM, Castelli W, Bacharach P. The aging thyroid. The use of thyroid hormone in older persons. JAMA 1989;261:2653-5.
6 Hall R, Scanlon MF. Hypothyroidism: clinical features and complications. Clin Endocrinol Metab 1979;8:29-38.

7 Use of Thyroid Function Tests Guidelines Development Group. UK guidelines for the use of thyroid function tests. British Thyroid Foundation, 2006.

8 Guidelines and Protocols Advisory Committee. Thyroid function tests: diagnoses and monitoring of thyroid function disorders in adults. Medical Services Commission, 2010.

9 Mandel SJ, Brent GA, Larsen PR. Levothyroxine therapy in patients with thyroid disease. Ann Intern Med 1993;119:492-502.

10 De Whalley P. Do abnormal thyroid stimulating hormone level values result in treatment changes? A study of patients on thyroxine in one general practice. Br J Gen Pract 1995;45:93-5.

11 Canaris G), Manowitz NR, Mayor G, Ridgway EC. The Colorado thyroid disease prevalence study. Arch Intern Med 2000;160:526-34.

12 Stall GM, Harris S, Sokoll LJ, Dawson-Hughes B. Accelerated bone loss in hypothyroid patients overtreated with L-thyroxine. Ann Intern Med 1990;113:265-9.

13 Lee JS, Buzkova P, Fink HA, Vu J, Carbone L, Chen Z, et al. Subclinical thyroid dysfunction and incident hip fracture in older adults. Arch Intern Med 2010;170:1876-83.

14 Somwaru LL, Arnold AM, Joshi N, Fried LP, Cappola AR. High frequency of and factors associated with thyroid hormone overreplacement and under-replacement in men and women aged 65 and over. I Clin Endocrinol Metab 2009;94:1342-5.

15 Cummings SR, Nevitt MC, Browner WS, Stone K, Fox KM, Ensrud KE, et al. Risk factors for hip fracture in white women. Study of Osteoporotic Fractures Research Group. N Engl I Med 1995;332:767-73.

16 Leslie WD, Anderson WA, Metge CJ, Manness LJ: Maximizing Osteoporosis Management in Manitoba Steering Committee. Clinical risk factors for fracture in postmenopausal Canadian women: a population-based prevalence study. Bone 2007;40:991-6.

17 Bauer DC, Ettinger B, Nevitt MC, Stone KL: Study of Osteoporotic Fractures Research Group. Risk for fracture in women with low serum levels of thyroid-stimulating hormone. Ann Intern Med 2001;134:561-8.

18 Meier C, Beat M, Guglielmetti M, Christ-Crain M, Staub JJ, Kraenzlin M. Restoration of euthyroidism accelerates bone turnover in patients with subclinical hypothyroidism: a randomized controlled trial. Osteoporos Int 2004;15:209-16.

19 Hadji P, Hars O, Sturm G, Bauer T, Emons G, Schulz KD. The effect of long-term, non-suppressive levothyroxine treatment on quantitative ultrasonometry of bone in women. Eur J Endocrinol 2000;142:445-50.

20 Duncan WE, Chang A, Solomon B, Wartofsky L. Influence of clinical characteristics and parameters associated with thyroid hormone therapy on the bone mineral density of women treated with thyroid hormone. Thyroid 1994;4:183-90.

21 Grant DJ, McMurdo ME, Mole PA, Paterson CR, Davies RR. Suppressed TSH levels secondary to thyroxine replacement therapy are not associated with osteoporosis. Clin Endocrinol (Oxf) 1993;39:529-33.

22 Gomez Acotto C, Schott AM, Hans D, Niepomniszcze H, Mautalen CA Meunier PJ. Hyperthyroidism influences ultrasound bone measurement on the os calcis. Osteoporos Int 1998;8:455-9.

23 Brennan MD, Powell C, Kaufman KR, Sun PC, Bahn RS, Nair KS. The impact of overt and subclinical hyperthyroidism on skeletal muscle. Thyroid 2006;16:375-80.

24 Sawin CT, Geller A, Wolf PA, Belanger AJ, Baker E, Bacharach P, et al. Low serum thyrotropin concentrations as a risk factor for atrial fibrillation in older persons. N Engl J Med 1994;331:1249-52.

25 Auer J, Scheibner P, Mische T, Langsteger W, Eber O, Eber B. Subclinical hyperthyroidism as a risk factor for atrial fibrillation. Am Heart / 2001;142:838-42.

26 Wejda B, Hintze G, Katschinski B, Olbricht T, Benker G. Hip fracture and the thyroid: a case-control study. J Intern Med 1995;237:241-7.

27 Sheppard MC, Holder R, Franklyn JA. Levothyroxine treatment and occurrence of fracture of the hip. Arch Intern Med 2002;162:338-43.

28 Flynn RW, Bonellie SR, Jung RT, MacDonald TM, Morris AD, Leese GP. Serum thyroid-stimulating hormone concentration and morbidity from cardiovascular disease and fractures in patients on long-term thyroxine therapy. J Clin Endocrinol Metab 2010;95:186-93.

29 Vestergaard P, Weeke J, Hoeck HC, Nielsen HK, Rungby J, Rejnmark L, et al. Fractures in patients with primary idiopathic hypothyroidism. Thyroid 2000;10:335-40.

30 Vestergaard P, Rejnmark L, Mosekilde L. Influence of hyper- and hypothyroidism, and the effects of treatment with antithyroid drugs and levothyroxine on fracture risk. Calcif Tissue Int 2005;77:139-44.

31 Riggs BL, Melton LJ 3rd. Involutional osteoporosis. N Engl J Med 1986;314:1676-86.

32 Hollowell JG, Staehling NW, Flanders WD, Hannon WH, Gunter EW, Spencer CA, et al. Serum TSH, T(4), and thyroid antibodies in the United States population (1988 to 1994): National Health and 
Nutrition Examination Survey (NHANES III). J Clin Endocrinol Metab 2002;87:489-99.

33 Center JR, Bliuc D, Nguyen TV, Eisman JA. Risk of subsequent fracture after low-trauma fracture in men and women. JAMA 2007;297:387-94.

34 Hoogendoorn EH, den Heijer M, van Dijk AP, Hermus AR. Subclinical hyperthyroidism: to treat or not to treat? Postgrad Med J 2004;80:394-8.

35 Surks MI, Ortiz E, Daniels GH, Sawin CT, Col NF, Cobin RH, et al. Subclinical thyroid disease: scientific review and guidelines for diagnosis and management. JAMA 2004;291:228-38.

36 Ross DS, Ardisson LJ, Meskell MJ. Measurement of thyrotropin in clinical and subclinical hyperthyroidism using a new chemiluminescent assay. J Clin Endocrinol Metab 1989;69:684-8.

37 Levy AR, O'Brien BJ, Sellors C, Grootendorst P, Willison D. Coding accuracy of administrative drug claims in the Ontario Drug Benefit database. Can / Clin Pharmacol 2003;10:67-71.

38 Austin PC, Daly PA, Tu JV. A multicenter study of the coding accuracy of hospital discharge administrative data for patients admitted to cardiac care units in Ontario. Am Heart / 2002;144:290-6.

39 Joseph KS, Fahey J: Canadian Perinatal Surveillance System. Validation of perinatal data in the Discharge Abstract Database of the Canadian Institute for Health Information. Chronic Dis Can 2009;29:96-100.

40 Hawker GA, Coyte PC, Wright JG, Paul JE, Bombardier C. Accuracy of administrative data for assessing outcomes after knee replacement surgery. J Clin Epidemiol 1997;50:265-73.

41 Richards J, Brown A, Homan C. The data quality study of the Canadian discharge abstract database. Achieving data quality in a statistical agency: a methodological perspective. Proceedings of Statistics Canada Symposium. Statistics Canada, 2001.

42 Leslie WD, O’Donnell S, Jean S, Lagace C, Walsh P, Bancej C, et al. Trends in hip fracture rates in Canada. JAMA 2009;302:883-9.

43 Mamdani M, Kopp A, Hawker G. Hip fractures in users of first- vs second-generation bisphosphonates. Osteoporos Int 2007;18:1595-600.

44 Alibhai SM, Duong-Hua M, Cheung AM, Sutradhar R, Warde P, Fleshner NE, et al. Fracture types and risk factors in men with prostate cancer on androgen deprivation therapy: a matched cohort study of 19,079 men. J Urol 2010;184:918-23.

45 Hux JE, Ivis F, Flintoft V, Bica A. Diabetes in Ontario: determination of prevalence and incidence using a validated administrative data algorithm. Diabetes Care 2002;25:512-6.

46 Hall S, Schulze K, Groome P, Mackillop W, Holowaty E. Using cance registry data for survival studies: the example of the Ontario Cancer Registry. J Clin Epidemiol 2006;59:67-76.

47 Altman DG, Bland JM. Interaction revisited: the difference between two estimates. BMJ 2003;326:219.

48 Trimpou P, Landin-Wilhelmsen K, Oden A, Rosengren A, Wilhelmsen L. Male risk factors for hip fracture-a 30-year follow-up study in 7,495 men. Osteoporos Int 2009;21:409-16.

49 Weller I, Schatzker J. Hip fractures and Alzheimer's disease in elderly institutionalized Canadians. Ann Epidemiol 2004;14:319-24

50 Rejnmark L, Vestergaard P, Mosekilde L. Fracture risk in patients treated with amiodarone or digoxin for cardiac arrhythmias: a nationwide case-control study. Osteoporos Int 2007;18:409-17.
51 Kanis JA, Johnell O, De Laet C, Johansson H, Oden A, Delmas P, et al. A meta-analysis of previous fracture and subsequent fracture risk. Bone 2004;35:375-82.

52 Klotzbuecher CM, Ross PD, Landsman PB, Abbott TA 3rd, Berger M. Patients with prior fractures have an increased risk of future fractures: a summary of the literature and statistical synthesis. J Bone Miner Res 2000;15:721-39.

53 Liu B, Anderson G, Mittmann N, To T, Axcell T, Shear N. Use of selective serotonin-reuptake inhibitors or tricyclic antidepressants and risk of hip fractures in elderly people. Lancet 1998;351:1303-7.

54 Richards JB, Papaioannou A, Adachi JD, Joseph L, Whitson HE, Prior JC, et al. Effect of selective serotonin reuptake inhibitors on the risk of fracture. Arch Intern Med 2007;167:188-94.

55 Chrischilles EA, Butler CD, Davis CS, Wallace RB. A model of lifetime osteoporosis impact. Arch Intern Med 1991;151:2026-32.

56 Riggs BL, Wahner HW, Seeman E, Offord KP, Dunn WL, Mazess RB, et al. Changes in bone mineral density of the proximal femur and spine with aging. Differences between the postmenopausal and senile osteoporosis syndromes. J Clin Invest 1982;70:716-23.

57 Dennis MS, Lo KM, McDowall M, West T. Fractures after stroke: frequency, types, and associations. Stroke 2002;33:728-34.

58 Pouwels S, Lalmohamed A, Leufkens B, de Boer A, Cooper C, van Staa T, et al. Risk of hip/femur fracture after stroke: a populationbased case-control study. Stroke 2009;40:3281-5.

59 Schneider DL, Barrett-Connor EL, Morton DJ. Thyroid hormone use and bone mineral density in elderly women. Effects of estrogen. JAMA 1994;271:1245-9.

60 Eriksen EF, Mosekilde L, Melsen F. Trabecular bone remodeling and bone balance in hyperthyroidism. Bone 1985;6:421-8.

61 Okosieme OE, Belludi G, Spittle K, Kadiyala R, Richards J. Adequacy of thyroid hormone replacement in a general population. QJM 2010; published online 24 November.

62 Sawin CT, Herman T, Molitch ME, London MH, Kramer SM. Aging and the thyroid. Decreased requirement for thyroid hormone in older hypothyroid patients. Am J Med 1983;75:206-9.

63 Mazziotti G, Porcelli T, Patelli I, Vescovi PP, Giustina A. Serum TSH values and risk of vertebral fractures in euthyroid post-menopausal women with low bone mineral density. Bone 2010;46:747-51.

64 Surks MI, Boucai L. Age- and race-based serum thyrotropin reference limits. I Clin Endocrinol Metab 2010;95:496-502.

65 De Laet C, Kanis JA, Oden A, Johanson H, Johnell O, Delmas P, et al. Body mass index as a predictor of fracture risk: a meta-analysis. Osteoporos Int 2005;16:1330-8.

66 Kopec JA, Esdaile JM. Bias in case-control studies. A review. Epidemiol Community Health 1990;44:179-86.

67 Ernster VL. Nested case-control studies. Prev Med 1994;23:587-90.

68 Essebag V, Genest J Jr, Suissa S, Pilote L. The nested case-contro study in cardiology. Am Heart J 2003;146:581-90.

69 Essebag V, Platt RW, Abrahamowicz M, Pilote L. Comparison of nested case-control and survival analysis methodologies for analysis of time-dependent exposure. BMC Med Res Methodol 2005;5:5.

70 Suissa S. Novel approaches to pharmacoepidemiology study design and statistical analysis. In: Strom BL, ed. Pharmacoepidemiology. 4th ed. Wiley, 2005:811-29.

Accepted: 28 February 2011 